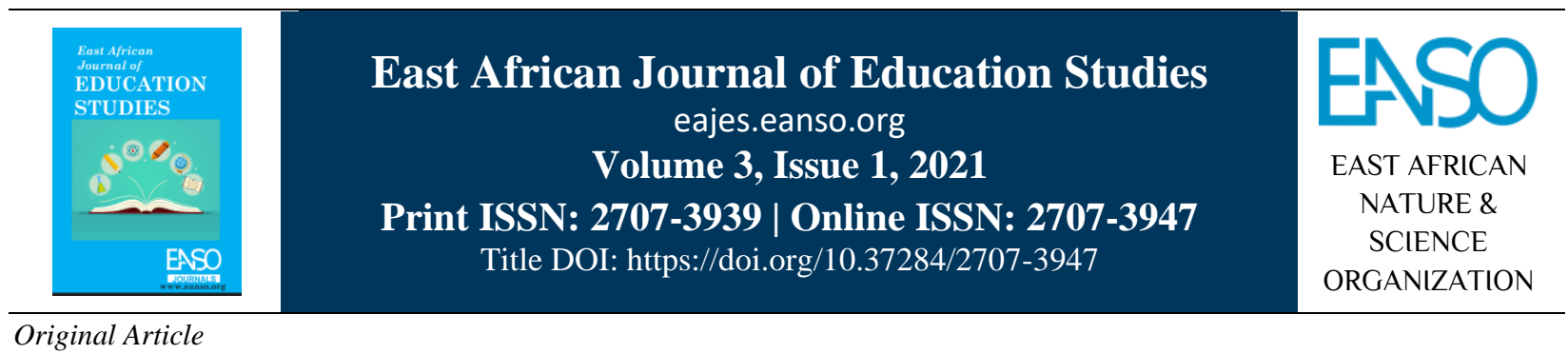

\title{
Knowing Process of Rural Secondary School Science Teachers: A Case of Rakai District in Uganda.
}

\author{
Disan Kuteesa, PhD ${ }^{* 1}$ \\ 1* Kyambogo University, P. O. Box 1, Kyambogo, Kampala-Uganda. \\ * ORCID: https://orcid.org/0000-0002-4979-648X; Correspondence Email: disanmugenyi75@gmail.com.
}

Article DOI: https://doi.org/10.37284/eajes.3.1.406

\section{Date Published: ABSTRACT}

09 September 2021 The study was an investigation of the Knowing Process of rural secondary science teachers in Uganda. The problem of the study was the poor performance of students

Keywords: in sciences in the rural secondary schools in Ugandan Certificate Examinations (UCE). The central point was to find out the beliefs of the rural secondary science Epistemology, teachers about how the educators come to know anything. A non-experimental Science, research design was employed in the study. The research was carried using a Teaching purposive sampling technique. Regarding data collection, the researcher administered fifty (50) questionnaires to fifty (50) teachers; interviewed ten teachers and carried out classroom observations often live lessons. The findings of the study revealed that teacher's conceptions about the mode of knowing to fall under three sources of knowledge, namely, authority, sense-perceptual experience, and reason. It was clear that teachers assume that learners do not have knowledge; hence the Bucket theory of mind is central in their teaching-learning process. Many teachers appeared to do things the way they were taught; in other words, a number of rural science teachers tended to be doing activities whose underlying assumptions they were not clear of. A functional approach to the teaching of Philosophy in Educational programs is recommended.

\section{APA CITATION}

Kuteesa, D. (2021). Knowing Process of Rural Secondary School Science Teachers: A Case of Rakai District in Uganda. East African Journal of Education Studies, 3(1), 246-252. https://doi.org/10.37284/eajes.3.1.406.

\section{CHICAGO CITATION}

Kuteesa, Disan. 2021. "Knowing Process of Rural Secondary School Science Teachers: A Case of Rakai District in Uganda". East African Journal of Education Studies 3 (1), 246-252. https://doi.org/10.37284/eajes.3.1.406.

\section{HARVARD CITATION}

Kuteesa, D. (2021) "Knowing Process of Rural Secondary School Science Teachers: A Case of Rakai District in Uganda", East African Journal of Education Studies, 3(1), pp. 246-252. doi: 10.37284/eajes.3.1.406. 


\section{IEEE CITATION}

D. Kuteesa, "Knowing Process of Rural Secondary School Science Teachers: A Case of Rakai District in Uganda", EAJES, vol. 3, no. 1, pp. 246-252, Sep. 2021.

\section{MLA CITATION}

Kuteesa, Disan. "Knowing Process of Rural Secondary School Science Teachers: A Case of Rakai District in Uganda". East African Journal of Education Studies, Vol. 3, no. 1, Sep. 2021, pp. 246-252, doi:10.37284/eajes.3.1.406.

\section{INTRODUCTION}

Considerations concerning the source of knowledge, which include philosophically divergent instruments of knowledge, sense perceptual experience, authority, reason, intuition, and revelation, have a significant bearing on educational issues and practice. However, it is doubtful whether secondary school teachers are conscious of modes of knowing in their choice of teaching/learning methods. It should clearly be stated that knowledge and truth may carry different meanings in that knowledge is the apprehension of reality, or the awareness and understanding of particular aspects of reality (Lemos, 2007). However, from classical accounts, for anyone to lay claim to knowledge, such claims must be true and believed with justifications. Hence, knowledge is sometimes defined as justified true belief, because to know something, one must believe in it, one's belief must be true and one's reason for believing it must be satisfactory in the light of some standard (Ayer, 1956) Thus, S' knows that P', if and only if:

- $\mathrm{P}$ is true (For $\mathrm{P}$ to be true, it must be independently verified by an independent researcher)

- $\mathrm{S}$ is sure that $\mathrm{P}$ is true

- $\mathrm{S}$ has the right to be sure that $\mathrm{P}$ is true

On the other hand, truth is the correspondence between concepts and reality; between the statements made about a particular reality and that reality spoken about. In this study, knowledge refers to truths at all levels. There is a need for secondary school teachers in rural areas to have clear conceptions about how knowledge is acquired in order for teaching/learning methods to be selected intelligently. In schools, students learn various forms of knowledge, skills and attitudes which call for a variety of methods. Such methods need to be consciously determined and an epistemological orientation is essential in this regard.

\section{Need for Epistemological Orientation}

It is important for the secondary school teachers in rural areas to be aware of the ways of knowing because this will help them in selecting what materials to teach, what teaching methods to use and where to place their emphasis during the teaching/learning processes. Maloba (1991) observed that teachers are central factors in the education of the child. Teachers are required to have a thorough understanding of methods of how students acquire knowledge, their personal care, upbringing, discipline, and active participation in the academic and co-curricular programme in the school.

This study sought to disclose rural science secondary school teachers' conceptions about the source of knowledge in the Rakai District. This was considered important because of the poor performance of students in the secondary school certificate examinations. It was assumed that teaching/learning methods employed by rural science teachers were reflections of their beliefs concerning the source of truth. Deford's (1985, p. 35) holds;

"Different ways of teaching and learning are not merely temperamental variations in regional outlooks, but at the bottom, there are ideological differences people hold."

This prompts a question of whether many rural secondary school science teachers do actually have clear conceptions of methods of knowing. The other question is, if they do, to what extent do these conceptions influence their choice of teaching/learning methods? There is a need to find out rural science secondary school teachers' conceptions about the method of knowing. According to Akinpelu (1981), it is in the area of epistemology that the relevance for education and especially for the classroom teaching and learning is the most noticeable. Henceforth, the search for truth 
and knowledge is the common task of both education and philosophy.

For a person to be called educated, he/she must not only possess specialized skills but certainly also possesses a considerable body of knowledge together with understanding (Akinpelu, 1981). This prompted the researcher to find out the source of reliable and dependable knowledge among rural secondary school teachers. Hab'imana (2001) argues that teachers to be effective, they should be aware of "ways of knowing" in their particular subject. This will keep them in selecting what materials to teach and where to put emphasis on their teaching of those subjects.

Nakibirige (1999) found out that teachers in Uganda were using teaching methods without Philosophical beliefs; many were doing things according to the way they were taught or by intuition. So, since according to Nakibirige (1999), many teachers were not aware of the proper teaching methods, there was a likelihood that rural secondary teachers are not aware of the generalized sources of knowledge. So Nakibirige's revelation further prompted the researcher to find out whether teachers in rural secondary schools are aware of the generalized sources of knowledge because educational enterprise to be fruitful, the teacher must be aware of the generalized methods of knowing.

\section{Instrument of knowledge}

Sense-perceptual experience

Authority

Reason

Intuition

Revelation

Sense-perceptual experience is one of the modes of knowing. Its theory is called Empiricism and it is confirmed by the evidence of senses, thus seeing, hearing, smelling, tasting and feeling. Authority is another source, according to the proponents of this source, a great amount of our knowledge is derived from the testimony of some authorities like textbooks, pamphlets, and teachers, among others. Reason is also a method of knowing and the

\section{Instruments of Knowledge}

To know is one of the most fundamental urges of man. Man, always wants to know the truth about his surroundings as well as the truth about himself. Otherwise, all his knowledge would be not only futile and senseless but also harmful and disastrous if it did not know the truth to guide him in all his actions. The ultimate aim of this search for truth is to know not only truth or truths but the truth purely and simply, implying reliable and valid knowledge. So, this called for a need to research on the generalized and right modes of knowing.

John Dewey asserted that the search for truth and knowledge is the common task of both education and philosophy. Teachers transmit various types of knowledge according to their disciplines. Thus, it is appropriate for a teacher to know the generalized sources of knowledge: how we know?

Do we know through sense- perception experience, Authority, Reason, Intuition, or Revelation? Source of knowledge refers to instruments of knowledge or modes of knowing, or ways through which knowledge is acquired. Philosophically there are different sources and theories of knowledge. These include:

Theory of knowledge

Empiricism

Authoritarianism

Rationalism

Intuitionism

Revelationism

adherents are called rationalists for them; knowledge is gained through reason or logical process unaccompanied by observation of the actual state of affairs. On the other hand, "tuition refers to a subconscious process in a person who intuits in a field in which he is well experienced, the proponents are known as intuitionist. The last source of knowledge is a revelation. According to this source, revealed knowledge is disclosed to a 
man from God. God is the father of all knowledge so to get reliable knowledge; we need to refer to the Bible, Koran or religious men and women.

The problem of the study lies in the inadequacy of awareness of rural science secondary school teachers' philosophical beliefs about the source of knowledge and their bearing on educational practice. Are rural secondary teachers for science aware of the generalized sources of knowledge? And if they do, which source is the most dominant? The other question is, is there a relationship between the source of knowledge and teaching-learning methods?

\section{Statement of the Problem}

Different educational philosophies and educationists place varying emphasis on these general sources of knowledge: sense-perceptual experience, authority, reason, intuition, and revelation.

Many authors had shown indirectly that teachers are not well versed with sources of knowledge; like Nakibirige (1999) wrote that teachers are not well versed with good teaching methods, yet there is a relationship between teaching methods and sources of knowledge, so there was a likelihood that students in rural secondary schools perform poorly because their teachers are not aware of the right sources of knowledge.

The problem of the study lay in the inadequacy of awareness of the commonly accepted modes of knowing among science teachers in rural secondary schools and establishing which one predominantly underlies their teaching strategies. The purpose of the study is to establish the structure of Philosophical beliefs among rural secondary science teachers about the source of knowledge in order to indicate its practical bearing on what goes on in the school with regard to teaching/learning methods. This study intends to establish rural secondary school science teachers' conceptions about the source of knowledge during the teachinglearning process.

\section{Scope}

The scope includes mainly an epistemological investigation of rural secondary teachers' conception about the issue of knowing in Uganda, with specific reference to schools in Rakai District. Also, the choice of this district aimed at minimizing the costs of the project since schools under the study was close together, within reasonable proximity of the researcher. Using the inductive methodology, it is projected that information gathered from teachers in Rakai District is a representation of all rural teachers' conceptions about the issue of knowing in Uganda.

Only ten schools were considered. Concerning content, the study was limited to the epistemological base of rural secondary teachers in Uganda. It undertook to determine whether secondary school teachers' conceptions have an influence on their general teaching methods in the educational situation.

\section{Significance of the study}

The study was expected to disclose rural secondary school teachers' conceptions about the source of knowledge in the context of the classroom. Understanding how science teachers' conceptions about the instruments of knowledge fundamentally influence the choice of teaching/learning methods is essential to educational practitioners. The findings of this study are therefore deemed to be of importance mainly in three ways:

- Helping educationists and" educational leaders in their assessment of teachers' practices by throwing fresh light on the means of transmission of knowledge in schools.

- Motivating secondary science teachers in service to reflect on the kind of fundamental beliefs they hold about the alternative teaching methods.

- Helping to stimulate new thinking about approaches regarding educating and training of secondary teachers in the teacher education programme.

\section{METHODOLOGY}

A non-experimental research design was employed in the study; hence the study was purely observational and the results are purely descriptive. The research was carried using a purposive sampling technique, where science teachers were selected in the sampled schools. Regarding data 
collection, the researcher administered fifty (50) questionnaires to fifty (50) teachers; interviewed four teachers, the number was determined by the concept of saturation. Further, the investigator carried out classroom observations of ten live lessons.

\section{DISCUSSION AND INTERPRETATION OF RESULTS}

This research question aimed at establishing secondary science teachers' conceptions about the source of knowledge. It stated: What is the Knowing process for rural science secondary teachers in Uganda? The findings of the study revealed that the predominant source of knowledge was authority (74\%) followed by sense perceptual experience $(22 \%)$ and reason (04\%). Table 1 presents the rural secondary teacher's beliefs about the source of knowledge. From Table 1, a big number agreed with authority as the most reliable source of knowledge (74\%) on the other hand; there were a moderate number of teachers who respectively agreed.

Table 1: Teachers' conceptions about the source knowledge

\begin{tabular}{lll}
\hline Source of knowledge & Response & Teacher \\
\hline Authority & Agreement & $74 \%$ \\
Intuition & Agreement & None \\
Revelation & Agreement & None \\
Sense-perceptual experience & Agreement & $22 \%$ \\
Reason & Agreement & $4 \%$ \\
Total & & $\mathbf{1 0 0 \%}$ \\
\hline
\end{tabular}

The findings can be attributed to the fact that all various sources of knowledge have something to offer to teachers. Consequently, rural secondary teachers do not conform to one specific source. What is more, it was hinted in the literature review that each source has definite areas of weakness as well as areas of strength from the educational process standpoint.

However as seen above, for many rural secondary teachers for science, the authoritative source is very pronounced, yet they are supposed to dispense scientific knowledge, yet true and dependable knowledge is one got from five senses that is feeling, seeing, hearing and smelling. Truly, there is a need to use teaching aid and practical in teaching all practical subjects. Referring to Akinpelu (1981), he observed that no school of thought could be regarded as sufficient to supply all a teacher needs to make him a successful professional. So, an educator may have to adopt ideas from a number of them in an eclectic fashion; likewise, an effective teacher needs to be aware of all sources of knowledge and employ or consult sources of knowledge depending on the subject. Field findings showed that rural secondary teachers aimed at pouring contents in the mind of the learner- (jug mug theory).
In relation to Interviews carried out, all the four participants reported that their knowing process is based on authoritarianism, they urged that students come for lessons without prior reading because the libraries are not well stocked with relevant books. So, the teachers dominate the teaching learning process. One teacher had this to say;

"Most of our students come from poor families, they cannot access relevant books, so what we do is to research and feed them with all they need in that lesson with little or no contribution from them." (Teacher XX)

The above assertion is a clear sign that teaching learning process of science lessons is dominated by the teachers, and this explains why performance is poor because students are not participative during the lessons hence forth learning does not take place. Further, all the four teachers asserted that they rarely seek for students 'contributions in class because they have much content to cover in very short time. In the schools visited, assessment time tables were displayed and much time is spent on weekly tests and monthly examinations, so the teachers urged that teacher centred methods are fast, they can cover much content in a very short time. 
In conformity, all the ten live lessons observed, the teachers were dominating the teaching learning process with no teaching aids. The learners listened attentively and were always instructed to copy notes from the chalk board. In some instances, the teachers dictated notes and learners 'role in class was to put down notes, this methodology promote cram work and also contributes to poor performance because learners are not given time to think on their own.

In summary, it may be said that whichever choice a teacher makes, is all right as long as one is fully convinced of the justification for his decision. In principle, this condition allows teachers to plan learning experiences within the context of what they believe to be a reliable source of knowledge. Scheffler (197, p. 85) further supports the view when he says:

"......If a justification is needed for a teachers' scholarly and theoretical sophistication regarding his work, it is not that, lacking it he cannot manage to teach, but having it, the quality of his effort and role is likely to be enhanced".

\section{CONCLUSIONS}

From the foregoing findings of the study, the conclusion is twofold; firstly, it was concluded that rural secondary science school teachers' beliefs are eclectic in nature. This means that there is no distinctive source of knowledge under which rural secondary teachers' beliefs fell, but mostly they put more emphasis on Authoritative sources. Secondly, the findings also indicate that most of the reasons for the choice of teaching method are not generally based on philosophical beliefs. Many teachers appeared to be doing things according to the way they were taught or by intuition. In other words, a number of teachers tended to be doing activities whose underlying assumptions they were not clearly aware of and clearly explains why many of their students perform poorly in Uganda Certificate of Education. For effective teaching, teachers irrespective of the financial stand of the school, need to be creative, innovative and assiduous if they are to realize academic excellence. Authority as a dominant source found in the field should be discouraged especially for all Sciences.

\section{RECOMMENDATIONS}

From the foregoing findings, discussions and conclusions, the researcher made four recommendations: The first recommendation is that: Teacher Education Programme should incorporate topics concerning philosophical beliefs and their role in the educational process. Also, workshops should be organized for all secondary school teachers, aimed at orienting them on the utmost need of having clear conceptions about the source of knowledge. Teachers need to know the limitations of different sources of knowledge so as to give dependable knowledge all the time in the educational situation. This is due to the fact that all sources of knowledge have limitations of which, according to the research carried out, many teachers are unaware of and may end up giving unreliable knowledge, i.e., "poison" to their students. This would help to ensure that teachers have clear conceptions about the source of knowledge as well as ensuring that philosophical beliefs play their expected role in guiding teachers' activities in the school. These workshops, conferences and symposiums should also be extended to tutors and lecturers of Philosophy of education to meet and share their knowledge, experience and lessons learnt. This would go a long way to help in devising means of how best they can improve the teaching of Philosophical beliefs in colleges and universities.

The second recommendation is to sensitize policymakers, educational planners and teacher educators about the role of Philosophical conceptions in the educational process. Lecturers and tutors of Philosophy should be facilitated so as to publish books simplifying the Philosophy of education. The unit of Philosophy of Education in Teacher colleges and Universities should be given more time as far as teaching is concerned so as to give enough "doze" of Philosophy to teachers during pre-service.

The third recommendation is that both in-service and pre-service teachers in secondary schools should be made aware, that there is a relationship between teaching methods and sources of knowledge, and philosophical reasoning should be given to them. This should be done by organizing refresher courses, seminars, tutorials for pre-service teachers, among others. 
The fourth recommendation is to make it clear to secondary school teachers that during the teachinglearning process students should be fully involved so as to develop their reasoning capability, the teacher acts as an awakener, always intercommunication should be emphasized for pupils to exhibit their native intelligence and develop their reasoning faculties, the knowledge they will get will be part of them forever.

\section{REFERENCES}

Akinpelu, J. (1981). An Introduction to Philosophy of Education. London: McMillan Publishers.

Ayer, A. J. (1956). The Problem of Knowledge. Penguin books

DeFord, D. E. (1985). Validating the construct of theoretical orientation in reading instruction. Reading research quarterly, 351367.

Hab'lmana. J. (2001). Philosophy of Education. Nkozi NTC.

Lemos, N. (2007). An introduction to the Theory of Knowledge. Cambridge University Press

Maloba, S. (1991) Education board of Governors rules and operational guidelines. MEO circular letter No ME 212718

Nakibirige, M. (1999). Primary and secondary teachers' conceptions about the nature of education in Kampala Schools. MED Dissertation. MUK

Scheffler, I. (1993). Reason and Teaching. London: Routledge and Kegan Paul. 